\title{
Três médicos e uma mãe
}

\author{
Three doctors and a mother \\ Tres médicos y una madre
}

Micaela Amaral Prata, Mariana Fonseca, Mafalda Gonçalves, Margarida Sousa, Lia Rocha

\section{Resumo}

A papilomatose laríngea, doença rara potencialmente fatal, carateriza-se pela proliferação de papilomas no trato respiratório, múltiplos, recorrentes, cuja etiologia é a infeção por papilomavírus humano (HPV). Menina, 21 meses, filha de mãe com serologia positiva para vírus da imunodeficiência humana $(\mathrm{VIH})$ e HPV. Em acompanhamento nas consultas de Pediatria do Desenvolvimento do Hospital, Pediatra Particular e Médico de Família (MF). Aos 18 meses, na consulta de acompanhamento do MF, a mãe preocupada salienta a fala sussurrada e choro rouco da filha com diagnóstico frequente de laringite aguda no Pediatra e MF nos últimos 3 meses, motivando a referenciação à Otorrinolaringologia e posterior diagnóstico de papilomatose laríngea. A abordagem da disfonia na criança evita o uso inapropriado de corticoides, inibidores da bomba de prótons e antibioticoterapia. Neste relato sobressai a desvantagem associada ao seguimento por múltiplos médicos, sendo o MF fundamental para reunir e integrar a informação clínica, permitindo a continuidade de cuidados.

\section{Abstract}

Laryngeal papillomatosis is a rare and potentially fatal disease characterized by the proliferation of recurrent respiratory papillomas, whose etiology is human papillomavirus (HPV) infection. We report a clinical case of a 21-month girl, whose mother is sero-positive to human immunodeficiency virus (HIV) infection and HPV. This girl attended multiple medical consultations: Development Pediatrics (at the hospital), private Pediatrician and General Practitioner (GP). At 18 months, in the GP surveillance consultation, the concerned mother referred whispered talking, hoarse crying and frequent diagnosis of acute laryngitis at the Pediatrician in the last 3 months. She was referenced to otorhinolaryngology with subsequent diagnosis of laryngeal papillomatosis. The approach to childhood dysphonia avoids inappropriate use of corticosteroids, proton pump inhibitors and antibiotics. This report highlights the disadvantage of the surveillance by multiple doctors and the key role of the GP in gathering and integrating clinical information, allowing the continuity of care.

\section{Resumen}

La papilomatosis laríngea, una enfermedad rara y potencialmente mortal, se caracteriza por la proliferación de papilomas respiratorios recurrentes, cuya etiología es la infección por el virus del papiloma humano (VPH). Se relata el caso de una niña de 21 meses, hija de una madre seropositiva al virus de la inmunodeficiencia humana $(\mathrm{VIH})$ y VPH. Vigilada en las consultas de Pediatría de Desarrollo del Hospital, Pediatría Privada y Médico de la Familia (MF). A los 18 meses, en la consulta de vigilancia del MF, la madre preocupada destaca habla susurrada, llanto ronco y diagnóstico frecuente de la laringitis aguda en la pediatra en los últimos 3 meses. Se referenció a otorrinolaringología con posterior diagnóstico de papilomatosis laríngea. El enfoque de la disfonía infantil evita el uso inapropiado de los corticosteroides, inhibidores de la bomba de protones y antibioterapia. En este informe se destaca la desventaja asociada al seguimiento por parte de varios médicos, y el papel clave del MF para reunir e integrar la información clínica, lo que permite la continuidad de la atención.

Como citar: Prata MA, Fonseca M, Gonçalves M, Sousa M, Rocha L. Três médicos e uma mãe. Rev Bras Med Fam Comunidade. 2016;11(38):1-7. http://dx.doi.org/10.5712/rbmfc11(38)1330
Palavras-chave:

Disfonia

Papillomaviridae

Controle de Acesso

Referência e Consulta

\section{Keywords:}

Dysphonia

Papilomaviridae

Gatekeeping

Referral and consultation

Palabras clave:

Disfonía

Papilomaviridae

Controle de acceso

Remisión y consulta

Fonte de financiamento: declaram não haver.

Parecer CEP:

não se aplica.

Conflito de interesses:

declaram não haver.

Procedência e revisão por pares: revisado por pares.

Recebido em: 17/05/2016.

Aprovado em: 26/09/2016. 


\section{Introdução}

A papilomatose laríngea carateriza-se pela proliferação de papilomas no trato respiratório, geralmente múltiplos e com tendência à recorrência. O local mais frequentemente afetado é a laringe, em especial as cordas vocais, a epiglote e as pregas vestibulares. Em $30 \%$ dos casos, pode afetar também locais extralaríngeos, tais como a cavidade oral e a traqueia. ${ }^{1}$

A etiologia da papilomatose é a infeção por papilomavírus humano (HPV), mais frequentemente os tipos 6 e 11. A infeção por HPV-11 é associada a doença mais grave e de pior prognóstico. ${ }^{1}$

A papilomatose laríngea tem uma distribuição etária bimodal, com um pico na infância e outro na idade adulta (entre os 20 e 30 anos), sendo classificada em forma juvenil ou forma adulta. Tem incidência de 1,8 por 100 mil habitantes na forma adulta e de 4 em 100 mil na forma juvenil, sendo a forma adulta mais frequente no sexo masculino e a juvenil com igual acometimento em ambos os sexos. ${ }^{1}$

A transmissão ocorre principalmente por via sexual no adulto e na criança é o resultado da transmissão vertical da infeção genital materna por HPV. Contudo, a transmissão ao feto não ocorre em todas grávidas com infeção HPV positivo, existindo alguns fatores de influência, tais como a condição imunológica materna e fetal, a carga viral, a existência de condilomas genitais e o parto por via vaginal. ${ }^{1-3}$

Um amplo estudo de coorte retrospetivo demonstrou um risco 231 vezes maior de papilomatose respiratória em crianças nascidas de mães com antecedentes de verrugas genitais. Apesar disto, o risco de papilomatose laríngea juvenil foi de apenas $1 \% .{ }^{1} A$ transmissão pode ainda ocorrer através do contacto de feridas cutâneas, pele ou objetos contaminados, nomeadamente durante atividades rotineiras como a troca de fraldas ou o banho. ${ }^{2}$

A literatura diz ainda que a cesariana eletiva por rotina é inadequada e não previne por si só a transmissão do vírus. ${ }^{2-4}$ No entanto, é o procedimento adequado na obstrução do canal do parto pelas lesões condilomatosas ou quando as dimensões das lesões ou a sua localização sugiram risco hemorrágico. ${ }^{4}$

A maioria das crianças apresenta a primeira manifestação da doença entre os 2 e os 4 anos de vida, sendo o sintoma mais comum a disfonia. O crescimento progressivo das lesões pode resultar em dispneia e estridor, e em casos raros a doença é fatal devido à obstrução severa das vias aéreas, disseminação broncopulmonar ou degenerescência maligna.

Esta doença é tanto mais agressiva quanto mais precoce for a primeira manifestação, portanto, nas crianças o quadro clínico é mais agressivo, especialmente se os primeiros sintomas aparecem antes dos 3 anos de idade. Este aspecto traduz-se na necessidade de um maior número de intervenções cirúrgicas para controle da doença e numa maior exuberância de sintomas na vida adulta. O tratamento consiste na exérese dos papilomas, a fim de manter a via aérea patente e melhorar a qualidade vocal. ${ }^{5}$

\section{Detalhamento do Caso}

\section{Identificação}

Relata-se o caso de uma criança do sexo feminino, com 21 meses de idade, natural e residente em Espinho, Portugal. Inserida numa família nuclear, na Fase II do Ciclo de vida familiar de Duvall ${ }^{6}$ e pertencente à Classe II da Classificação socioeconômica de Graffar (Figura 1). ${ }^{7}$ 


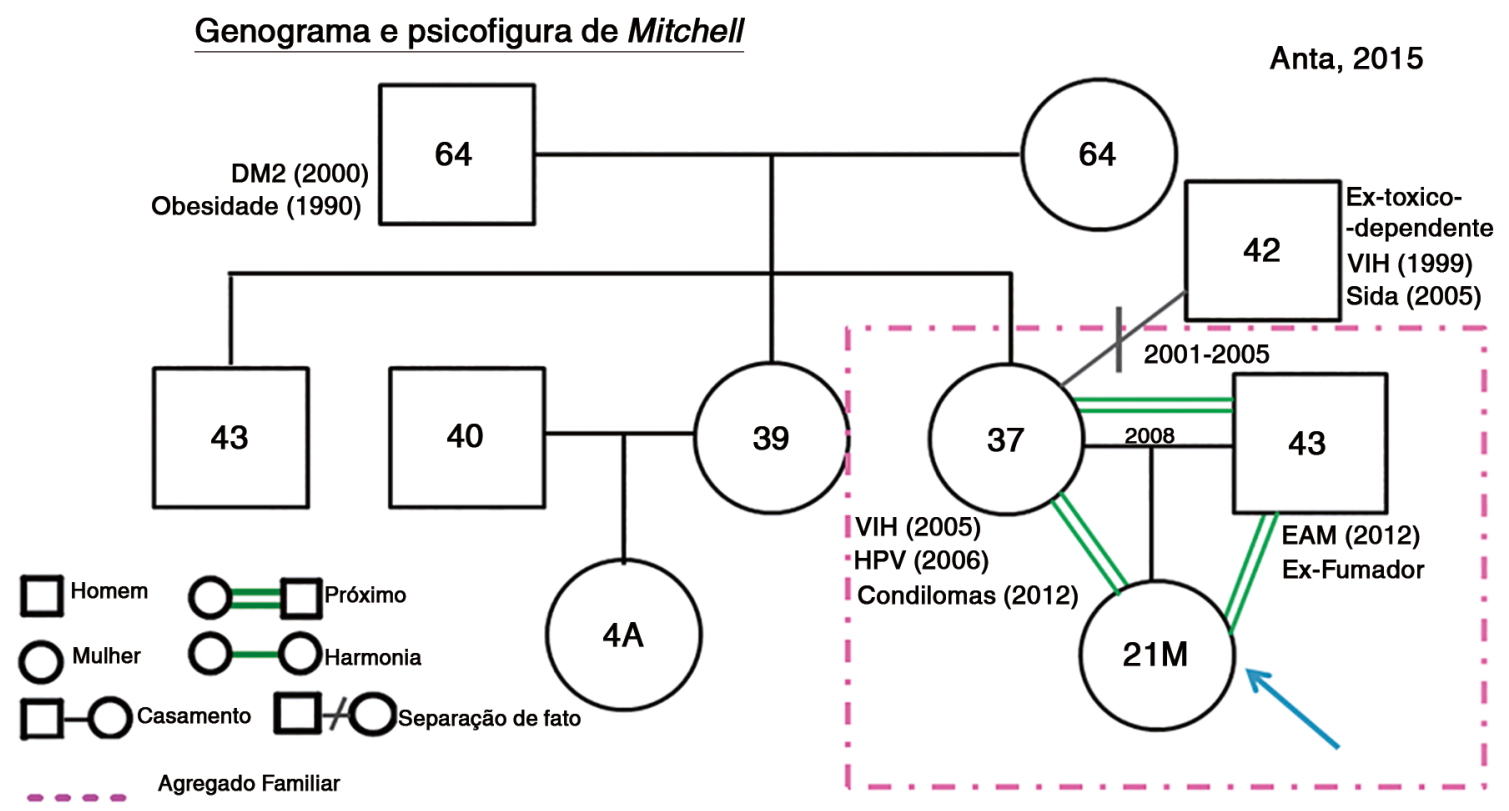

Figura 1. Genograma familiar ${ }^{8}$ e Psicofigura de Mitchell ${ }^{9}$ pela perspectiva da mãe.

\section{Antecedentes Pessoais}

Criança nascida por cesariana à $38^{a}$ semana de gestação, após gravidez de risco devido à mãe com vírus da imunodeficiência humana (VIH) e HPV positivos, planejada e acompanhada no Hospital de referência e no Obstetra particular. Como intercorrência é de referir o diagnóstico de condilomas genitais no 10 trimestre tratados com terapêutica local.

Ao nascimento, apresentava APGAR 9/10, estatura de $46 \mathrm{~cm}$, peso de $3235 \mathrm{~g}$ e perímetro cefálico (PC) de $34,5 \mathrm{~cm}$. O período neonatal não teve intercorrências, tendo sido afastada a infecção do recém-nascido por VIH e realizada profilaxia durante um mês com terapêutica antirretrovírica. Não foi realizado aleitamento materno.

A doente foi acompanhada na consulta de desenvolvimento de pediatria do Hospital de referência desde o primeiro mês de idade, pelos antecedentes maternos e, na consulta de Saúde Infantil do médico de família (MF), com registro de boa evolução estaturo-ponderal e psicomotora e sem queixas ou intercorrências de relevo até os 15 meses. Foi também acompanhada também no pediatra particular.

A doente apresenta o Plano Nacional de Vacinação (PNV) atualizado e tomou ainda vacinas não contempladas no PNV, como a Prevenar 13 e a Rotateq. Não são conhecidas alergias medicamentosas ou alimentares e não realiza medicação habitual. Não frequenta a creche até a data.

\section{Antecedentes Familiares}

A mãe teve diagnóstico de soropositividade para VIH em 2005 e de infeção por HPV em 2006, com desenvolvimento de condilomas durante a gravidez, tratados com terapêutica local.

O pai é ex-fumante desde 2012, com uma carga tabágica de 40 Unidades Maço Ano, e teve um infarto agudo de miocárdio em 2012. 


\section{História da Doença Atual}

Em maio de 2014, com 15 meses de idade e durante a consulta de saúde infantil e juvenil com o MF, a mãe refere queixas compatíveis com disfonia: "voz e choro roucos" (sic) desde a véspera, após episódio prolongado de choro. Nega febre, rinorreia, tosse, estridor, dispneia e sem noção de ingestão de corpo estranho. Ao exame objetivo, a criança apresenta-se pouco colaborante, com choro rouco, sem outras alterações. Os parâmetros antropométricos mantêm-se nos mesmos percentis $(P)$ desde a nascença (estatura P<3; peso P3-15; PC P15-50). Assume-se o diagnóstico de laringite aguda e propõe-se terapêutica com ibuprofeno $5 \mathrm{mg} / \mathrm{kg} /$ dose.

Dez dias após este episódio, recorre à consulta aberta da Unidade de Saúde Familiar com quadro compatível com gastroenterite aguda, sendo registado ao exame objetivo choro rouco e desidratação ligeira.

Aos 18 meses, na consulta de acompanhamento de saúde infantil com o MF, a mãe mostra-se bastante preocupada e relata várias idas ao Pediatra nos últimos três meses, com diagnóstico de laringite aguda. Descreve episódios frequentes de disfonia "voz rouca mesmo sem estar constipada" (sic), e refere fala sussurrada desde as primeiras palavras e, recentemente, noção de fadiga da voz.

A disfonia apresentava agravamento com o esforço da voz, melhoria em clima quente e seco, ausência de relação com o período do dia ou com infeções respiratórias. Quando questionada, a mãe assume que o choro da filha é rouco desde há aproximadamente três meses. Nega tosse, pieira, estridor, dispneia, rinorreia, esternutos de repetição, antecedentes de regurgitação, assim como exposição a irritantes ambientais, alergênios ou medicação. Objetivamente, verifica-se uma subida no percentil do peso comparativamente às consultas anteriores (Estatura P3-15; Peso P15-50; PC P15-50), sem alterações de relevo.

Portanto, estávamos perante um quadro progressivo de disfonia intermitente de longa data inexplicado, o que motivou a referenciação da criança para a consulta externa de Otorrinolaringologia com prioridade urgente. Aos 21 meses, realizou laringoscopia, tendo sido detectada uma neoformação das cordas vocais e diminuição da fenda glótica, pelo que foi agendado bloco operatório para laringoscopia terapêutica prioritária. A presença de papilomas levou à realização de cordectomia vocal por laser, cuja histologia confirmou o diagnóstico de Papilomatose Laríngea Juvenil.

\section{Discussão}

A Papilomatose Laríngea é uma doença rara, mas potencialmente fatal. Na pesquisa efetuada da literatura foi possível constatar que estão publicados relatos de caso sobre papilomatose laríngea recorrente juvenil, no entanto, a maioria deles descreve apresentações da doença numa fase avançada, nomeadamente com sinais de alarme como primeira manifestação e mesmo após o desenvolvimento de complicações tardias, tais como degenerescência maligna. ${ }^{10-12}$ Deste modo, a maioria destes relatos dizem respeito à perspectiva dos cuidados de saúde secundários.

Se por um lado o papel de gatekeeping (controle de acesso) do MF protege o paciente de procedimentos desnecessários e de complicações iatrogênicas, ${ }^{13}$ associando-se mesmo a melhores desfechos comparativamente com a referenciação autônoma pelo paciente, ${ }^{14}$ por outro lado, pode estar associado ao risco de subtratamento na ausência de um encaminhamento adequado e atempado aos 
cuidados de saúde secundários. No entanto, existe uma fraca evidência que suporte a associação entre o gatekeeping e piores desfechos. ${ }^{15}$

Neste sentido, o MF deve estar familiarizado com esta afecção, estar apto a identificar sinais de alerta e orientar, sendo de elevada importância a correta abordagem da disfonia na criança. A anamnese e o exame objetivo, especialmente a avaliação da qualidade da voz e do choro, têm um papel fundamental na realização dos diagnósticos diferenciais da disfonia na criança.

Alguns dos mais frequentes são a laringite crônica (infeciosa, alérgica, refluxo laringofaríngeo), a paresia/paralisia das cordas vocais, as malformações laríngeas congênitas, os nódulos das cordas vocais e os tumores, nomeadamente os papilomas e hemangiomas. ${ }^{1,5}$

Neste contexto é fundamental conhecer a idade de início (no recém-nascido ou posteriormente) e tempo de evolução (aguda, crônica, rapidamente progressiva); fatores de agravamento (matinal, sazonal, infeções vias aéreas superiores); sintomas associados (tosse, pieira, estridor, sinais de dificuldade respiratória, regurgitação, vômitos, disfagia) e os antecedentes pessoais e familiares (parto, intubação, cirúrgicos, medicação, perda auditiva).

Existem alguns sinais de alarme que devem motivar a referenciação ao serviço de urgência e que o MF deve conhecer, nomeadamente a presença de disfonia no recém-nascido, sinais de dificuldade respiratória, disfonia após trauma, sintomas rapidamente progressivos ( $<2$ semanas), presença de dor ou estridor e a ingestão de corpo estranho. ${ }^{5}$

Excluídos os sinais de alarme e perante a limitação do MF na realização do exame objetivo completo, a criança com disfonia deve ser referenciada para realizar laringoscopia, se a disfonia for socialmente inadequada, ou perante um quadro progressivo ou de longa duração inexplicado (>3 meses). ${ }^{5}$

Neste relato de caso estamos perante um quadro progressivo de disfonia intermitente de longa duração. A idade de início do quadro, assim como o seu caráter intermitente, afastam a hipótese de doença congênita. Tratava-se de uma criança que não frequenta o infantário, cuja disfonia não tinha relação com o período do dia e sem sintomas acompanhantes. Deste modo e perante um exame objetivo sem alterações, foram afastadas as hipóteses de asma, rinite, sinusite e refluxo laringolaríngeo. Portanto, a laringoscopia foi fundamental para prosseguir a investigação deste quadro de longa duração inexplicado.

No entanto, nos três meses precedentes a criança recorreu várias vezes ao pediatra particular, com queixas compatíveis com disfonia, sendo várias vezes diagnosticada com laringite aguda e medicada com corticoterapia oral. A abordagem correta da disfonia na criança permite o diagnóstico de patologias graves, assim como a diminuição do uso inapropriado de corticoides, inibidores da bomba de prótons e de antibioticoterapia. ${ }^{16}$

Está patente neste caso a importância dos antecedentes familiares no raciocínio clínico. O genograma ${ }^{8}$ é um instrumento de avaliação familiar que, apesar de ter pouca aplicabilidade em famílias pouco numerosas, constitui um bom método de diagnóstico, nomeadamente pelo destaque dos antecedentes familiares. No entanto, este caso mostra-nos que conhecer os antecedentes familiares pode não ser suficiente para chegar ao diagnóstico. É igualmente importante conhecer as possíveis consequências para a descendência dos problemas diagnosticados nos progenitores, permitindo reconhecer de forma precoce as manifestações durante o acompanhamento da criança, jovem ou mesmo do adulto. 
O título deste relato de caso advém do fato de que, apesar da criança ser acompanhada por três médicos, a preocupação da mãe foi o elemento fundamental para a realização do diagnóstico. A mãe conseguiu perceber que existia um problema com a sua filha não valorizado pelos médicos nessa altura, apesar de ser a primeira filha do casal e se encontrar na fase II do ciclo de vida familiar de Duvall.

A psicofigura de Mitchell $^{9}$ revelou um bom suporte familiar e uma relação próxima entre os pais e a criança, o que pode ter constituído uma vantagem para chegar ao diagnóstico, lidar com os exames complementares de diagnóstico invasivos, assim como promover a futura adesão terapêutica, nomeadamente a terapia da fala.

Por outro, lado percebemos que podem surgir algumas desvantagens associadas ao fato do paciente ser seguido em vários médicos, nomeadamente o tipo de queixas em cada uma das consultas ser diferente. Além disso, os registros clínicos encontram-se dispersos pelos diferentes médicos, podendo simular a diminuição da frequência de determinada queixa ou mesmo a sua inexistência.

O MF encontra-se numa posição privilegiada para a reunir e integrar a informação clínica, permitindo a continuidade de cuidados. Neste sentido, a plataforma de dados da saúde, o Boletim de Saúde Infantil e Juvenil e os registros informáticos são instrumentos chave à prática clínica.

O risco dos cuidados fragmentados é a divisão da responsabilidade, podendo levar ao que Ballint chamava de "conluio de anonimato", referindo-se a decisões tomadas sobre o doente sem a clara compreensão de quem é o responsável por ele. ${ }^{17}$ Deste modo, sem a continuidade de cuidados e a responsabilidade do MF, os cuidados fragmentados podem ser um desperdício e perigosos. ${ }^{17}$

Nesta faixa etária, a consulta de acompanhamento está bastante orientada para a detecção de problemas relacionados com o desenvolvimento psicomotor da criança, mas neste relato de caso sobressai a importância da questão básica que o MF faz "Como passou desde a última consulta?" ou "Neste último período houve algo de novo?". O MF deve, portanto, questionar e registrar a existência de intercorrências, a recorrência ao serviço de urgência, à consulta aberta, a outros médicos e a eventual necessidade de tratamentos.

\section{Referências}

1. Zalvan $\mathrm{CH}$, Jones J. Hoarseness in children: Etiology and management. In: UpToDate. 2015 [cited 2015 may 5]. Available from: www.uptodate.com

2. Lacour DE, Trimble C. Human papillomavirus in infants: transmission, prevalence, and persistence. J Pediatr Adolesc Gynecol. 2012;25(2):93-7. doi: 10.1016/j.jpag.2011.03.001

3. Smith EM, Parker MA, Rubenstein LM, Haugen TH, Hamsikova E, Turek LP. Evidence for vertical transmission of HPV from mothers to infants. Infect Dis Obstet Gynecol. 2010;2010:326369. doi: 10.1371/journal.pone.0066368

4. Moutinho JAF. Consenso sobre infeção por HPV e neoplasia intraepitelial do colo da vulva e vagina. Sociedade Portuguesa de Ginecologia - Secção Portuguesa de Colposcopia e Patologia Cervico-vulvovaginal. Coimbra; 2014.

5. Zalvan $\mathrm{CH}$, Jones J. Hoarseness in children: Evaluation. In: UpToDate. 2015 [cited 2015, may 5]: Available from: http:// www.uptodate.com/contents/hoarseness-in-children-evaluation?source=search_result\&search=Hoarseness+in+childre n\&selectedTitle=2\%7E150

6. Duvall EM, Miller BC. Marriage and family development. 6th ed. New York: Harper \& Row; 1985.

7. Graffar M. Une methode de classification sociales d'echantillons de populatión. Courrier. 1956;6:445-59.

8. Rebelo L. Genograma familiar. O bisturi do médico de família. Rev Port Clin Geral. 2007;23(3):309-17. doi: http://hdl.handle. net/10451/5655 
9. Rebelo L. A família em Medicina Geral e Familiar: conceitos e práticas. Lisboa: Verlag Dashofer; 2011.

10. Boo WH, Rajan P, Ching SM, Lee PY. Juvenile recurrent respiratory papillomatosis: A rare masquerade of asthma. Malays Fam Physician. 2015;10(2):45-8.

11. Egambaram S, Abdulla G. Juvenile Laryngeal Papillomatosis: An Unexpected Cause of Stridor. Phys Pract. 2008 [Internet] [citado 2016 Nov 28]. Disponível em: http://www.physicianspractice.com/articles/juvenile-laryngeal-papillomatosisunexpected-cause-stridor

12. Rastogi M, Srivastava M, Bhatt MLB, Srivastava K, Bhatia N. Laryngeal carcinoma in a 13-year-old child. Oral Oncol Ext. 2005;41(9):207-10. http://dx.doi.org/10.1016/j.00e.2005.06.002

13. Starfield B. Is primary care essential? Lancet. 1994;344(8930):1129-33. http://dx.doi.org/10.1016/S0140-6736(94)90634-3

14. Roos NP.Who should do the surgery? Tonsillectomy-adenoidectomy in one Canadian province. Inquiry. 1945;16(1):73-83.

15. Franks P, Clancy CM, Nutting PA. Gatekeeping revisited--protecting patients from overtreatment. N Engl J Med. 1992;327(6):424-9. doi: 10.1056/NEJM199208063270613

16. Schwartz SR, Cohen SM, Dailey SH, Rosenfeld RM, Deutsch ES, Gillespie MB, et al. Clinical practice guideline: hoarseness (dysphonia). Otolaryngol Head Neck Surg. 2009;141(3 Suppl 2):S1-S31.

17. Freeman T, ed. McWhinney's Textbook of Family Medicine. 4th ed. New York: Oxford University Press; 2016.

Micaela Amaral Prata. Unidade de Saúde Familar Anta; Agrupamento de Centros de Saúde Grande Porto VIII - Espinho/Gaia. Portugal. miprata@gmail.com (Autora correspondente)

Mariana Fonseca. Unidade de Saúde Familar Anta; Agrupamento de Centros de Saúde Grande Porto VIII - Espinho/Gaia. Portugal. marianapereirafonseca@gmail.com

Mafalda Gonçalves. Unidade de Saúde Familar Anta; Agrupamento de Centros de Saúde Grande Porto VIII - Espinho/Gaia. Portugal. mafaldaferreiragoncalves@gmail.com

Margarida Sousa. Unidade de Saúde Familar Anta; Agrupamento de Centros de Saúde Grande Porto VIII - Espinho/Gaia. Portugal. fmargarida.usf.anta@gmail.com

Lia Rocha. Unidade de Saúde Familar Anta; Agrupamento de Centros de Saúde Grande Porto VIII - Espinho/Gaia. Portugal. lia.usf.anta@gmail.com 